\title{
VIRTUAL REALITY IN TEACHING OF FOREIGN LANGUAGES
}

\author{
Saya Mukhametkaliyeva
}

\author{
KazUIR \& WL, Ablai Khan University, Almaty, Kazakhstan
}

\begin{abstract}
The study of the mechanisms of language and speech abilities has shown that the most effective method of learning a foreign language is the method of full immersion, since students enter the natural language environment and are in it constantly. But the learning process in the classroom, no matter how organized and communicative it may be, cannot replace the real teaching experience. Since the most important factors for effective learning of a foreign language are the language environment and motivation, therefore, the development of new motivational language learning environments, including virtual reality (VR), is the main elements of the learning process. In such an educational space, virtual reality helps students to understand phenomena and situations that cannot be understood and explained using traditional methods in order to become part of the real world through modeling. In general, virtual reality is an ideal learning environment, and the possibilities of its technologies for learning have an extremely high potential for application.
\end{abstract}

\section{INTRODUCTION}

Education and science play a key, system-forming role in the formation of human capital, in the socio-economic development of any territory, ensuring the vital activity and progress of society. In turn, human capital is the most important factor that determines the inclusion of the territory in the processes of post-industrial development, the formation of a system of environmentally sustainable development, the creation of a "green" economy, etc. [Astrakhantseva, 2017]. Open education provides increased financial literacy and increased freedom to do business. To identify the challenges and trends in the development of the region's scientific and educational complex, its key competitive advantages, and formulate strategic development goals, the innovative complex methodology AV Region Galaxy Model, developed by AV Group, was used. The foresight technology of inclusion of the E-Learning platform of open education in the decomposition of the strategic goals of regional development has been applied. The methods of sociological surveys, comparative analysis and economic and statistical research methods were used [Gurova, Zabolotnikova, 2017].

Originally the epithet "virtual" (from Latin virtus - imaginary) It was introduced by experts in quantum physics to denote ephemeral (unobservable) elementary particles that arise and exist only in the process of interaction of other particles. N.A. Nosov notes that in ancient philosophy and medieval scholasticism, the term virtus (virtual) was one of the central categories denoting the possible, potential, related to reality of a different (higher) order. However, then its meaning radically changed: "virtual" began to mean the opposite of the material, ephemeral, trying to artificially recreate reality. Subsequently, this concept was used to denote three-dimensional computer macromodels, and then quickly expanded its terminological boundaries, becoming one of the universal characteristics of information activity as such.

S. McGlashan and T. Exling understand VR as "a graphical two-dimensional or threedimensional interface for interaction between a user and a computer, which is applied to computer simulated environments that can simulate places in the real world, as well as in imaginary worlds". Having analyzed the definitions of the concept of "virtuality" proposed by various researchers, we can highlight its main features relevance:

- virtual objects exist only up to the present, only "here and now"; * autonomy: the laws of the existence of virtual objects do not coincide with the laws of the existence of the reality that generates them

- generation: these objects are produced by the activity of some other reality external to them, and exist only as long as this activity lasts 
- interactivity: virtual objects can interact with the reality that generates them as ontologically independent of it

- ephemeral: virtual objects are artificial and changeable;

- immateriality of impact: virtual objects, not being material, can produce effects characteristic of real ones; fragmentation: the freedom to enter virtual reality and the freedom to exit it provide the possibility of arbitrary interruption and resumption of its existence. In pedagogy, "VR" is mainly used as a special information space where a student can receive certain information, make contacts, elements of scientific, educational and project activities.

\section{Justification of the choice of articles and goals and objectives}

With the introduction of new technologies, the teacher will have 2 ways to conduct classes:

1st way: "Student - consumer". The student simply puts on his glasses and begins to consume the information that the teacher has prepared.

2nd way: "The disciple is the creator". In this case, the child begins to study programming, modeling and other subjects that are of interest to him, and already on the basis of his knowledge, he creates an educational project within the framework of the "Individual project" lesson. From elementary grades to graduation, he will develop his project.

Naturally, the level of training of teachers who will work with virtual or augmented reality should be higher, so they will have to take the appropriate refresher courses. After that, they will be able to create mini-lessons in virtual reality on special platforms.

\section{SCIENTIFIC RESEARCH METHODOLOGY}

So how can virtual and augmented reality are applied in the classroom? [Yarmukhametova, 2020]

In chemistry lessons, you can conduct experiments that are interesting, but very dangerous. And for safety reasons, these experiments are not conducted in schools. Therefore, with virtual reality it will become possible and cognitive. There are already special applications for such experiments, for example, "MEL Chemistry VR app". There is also an application "AR VR Molecules Editor", in which you can design the bonds of molecules, and by pointing your phone at a piece of paper with a chemical bond formula, you can study a 3D model of this molecule. The advantage of this technology is that you can see not only the reaction itself externally, but also see the whole process down to the atom.

In this regard, methodological guidelines have been developed and created for students that contain basic information for working with Google apps, necessary for creating and developing academic writing skills and abilities [Chalmers, Howard, Moir, 2009].

Registering a Google account

To maximize the use of Google apps, users need a Google account. First you need to log in to google.com to register a Google account. Click the blue «Sign in» (Picture 1) button in the upper right corner to go to the «Create a Google Account» page (Picture 2). The registration procedure is very simple. First enter your name and create a new email address and password. In the next line indicate the date of birth, month, year, gender and phone number to confirm registration and click «Next» (Picture 3). This way, you sign up for a Google account where all Google services are available. After registration, welcome messages from the Google team will be sent to your mailbox.

\section{CONCLUSION}

With the development of VR\&AR technologies, the number of vacancies for the places of developers of virtual and augmented reality applications will increase. After all, virtual reality is the future; it can be applied in all spheres of life, from entertainment to education. Therefore, the interest of parents and their children in these technologies will also increase [Vayndorf-Sysoeva, 2017]. The consequence of this phenomenon is the creation of special classes, in which children will additionally be taught how to create VR\&AR games, applications, drawings, projects, digital paintings, starting 
from elementary grades. Then they choose a topic / area that interest them, and develop it before leaving school in the framework of the "Individual project" lesson. For example, at the end of school, the student presents his work in the form of an application, in which you can examine and study the structure of the frog in detail. Or it can be a game in which a person using VR glasses is possessed by Stalin's body, and important moments in the life of this person live on his behalf. There are many variations; this method gives a wide space for creativity. This teaching method will allow teaching students to use the tools, and then they themselves must decide in which area these tools are used for them.

In conclusion, it's crucial to mention that great prospects for development are opening up for schoolchildren and teachers. In the near future, it will become possible for students to closely interact with augmented and virtual reality, which will develop their creativity and improve the quality of education. But in order to achieve this, a number of problems will need to be overcome.

\section{REFERENCES:}

Astrakhantseva Z.E. (2017) Virtual reality to help the modern teacher. Retrieved from: http://platonsk.68edu.ru/wp-content/uploads/2017/07/Doklad-Virtualnaya-realnost-v-pomoshhsovremennomu-pedagogu.pdf

Gurova T.I., Zabolotnikova V.S. (2017) Intelligent information systems of education. Professional development of teaching staff in the context of education renewal: Collection of materials of the VIII City Scientific and Practical Conference. M .: OOO "A-Prior"

Yarmukhametova I.V. (2020) The use of VR and AR technologies in teaching / Collection of articles and abstracts of the student open conference. $\mathrm{M}$.

Abraham A., von Cramon D.Y. Reality = Relevance: Insights from Spontaneous Modulations of the Brain's Default Network when Telling Apart Reality from Fiction. Retrieved from: http://www.plosone.org/article/info:doi/10.1371/journal.pone.0004741

Carlson W. A Critical History of Computer Graphics and Animation (2003) // [Pecyp The Department of Industrial, Interior, and Visual Communication of The College of The Arts of The Ohio State University]. Retrieved from http://design.osu.edu/carlson/history/lessons.html

Chalmers A.G., Howard D., Moir C. (2009) Real Virtuality: A Step Change from Virtual Reality. // Proc. Spring Conference on Computer Graphics SCCG'09. ACM SIGGRAPH Press, 2009. P.p. $15-22$.

Vayndorf-Sysoeva M. E. (2017) Methodology of distance learning: a textbook for universities / M. E. Weindorf-Sysoeva, T. S. Gryaznova, V. A. Shitova; under total. ed. M.E. Weindorf-Sysoeva. Moscow: Yurayt Publishing House. 